\title{
DETERMINING THE TRANSVERSE SHEAR STIFFNESS OF STEEL STORAGE RACK UPRIGHT FRAMES
}

\author{
Benoit P. Gilbert ${ }^{\mathrm{a}}$, Kim J.R. Rasmussen ${ }^{\mathrm{b}}$, Nadia Baldassino ${ }^{\mathrm{c}}$, Tito Cudini ${ }^{\mathrm{d}}$, Leo Rovere ${ }^{\mathrm{d}}$ \\ ${ }^{a}$ Griffith School of Engineering, Griffith University, Gold Coast QLD 4222, Australia (corresponding author, \\ email: b.gilbert@griffith.edu.au,Phone: +6175552 8577,) \\ ${ }^{b}$ School of Civil Engineering, The University of Sydney, Sydney NSW 2006, Australia (email: \\ kim.rasmussen@sydney.edu.au,Phone: +61293512125) \\ ${ }^{c}$ Department of Mechanical and Structural Engineering, University of Trento, via Mesiano 77, 38123 Trento \\ (TN), Italy (email: nadia.baldassino@unitn.it, +39461282533) \\ ${ }^{d}$ Modulblok S.p.A., via Vanelis 6, 33010 Pagnacco (UD), Italy (email: tito.cudini@modulblok.it, Phone: +39 \\ $432660145)$
}

Abstract: The stability of steel storage racks in the cross-aisle direction is typically ensured by cold-formed steel bolted upright frames. Sensitive to second-order effects, accurately determining the shear stiffness of these frames is essential for seismic design and for ensuring the stability of the rack, especially for high-bay racks and racks supporting the building enclosure, where the outer rack frames must withstand cross-aisle horizontal actions due to wind loading. The main international racking specifications adopt different approaches to determining the shear stiffness of cold-formed steel storage rack upright frames. The Rack Manufacturers Institute (RMI) Specification conservatively uses Timoshenko and Gere's theory. The European Specification EN 15512 recommends testing, however it is not clear whether the shear stiffness obtained using the recommended test procedure is correct. The newly revised Australian Standard AS 4084 adopted the European approach but also introduced an alternative test method for determining the combined bending and shear stiffness of upright frames in the transverse direction. This paper reviews and analyses the factors influencing the shear deformation of cold-formed steel bolted upright frames and introduces the alternative test set- 
up adopted in the revised Australian Standard. 36 upright frames have been tested using the two test methods, and experimental results are presented, discussed and compared with Finite Element analysis results. Recommendations on how to use the test outcomes in design are also provided. Based on these recommendations, the paper shows that the two test methods are not equivalent and yield different results for the transverse shear stiffness of upright frames.

\section{INTRODUCTION}

Steel storage racks are common structures used in industry to store goods on pallets. They act as freestanding structures in their own right and are designed as lightly as possible, yet able to carry heavy loads. Typically made of cold-formed steel profiles, their stability is often solely ensured by the base plate to floor connections and the pallet beam to upright connections in the down-aisle direction [1-2] (Fig. 1). In the cross-aisle direction, stability is ensured by upright frames consisting of uprights connected by bracing members as shown in Fig. 1 and Fig. 2. The bracing members are typically bolted to the upright flanges and made from cold-formed lipped Cee-sections. There may be one or two bracing members connected to the upright at the same bracing point, as shown in Fig. 2. Circular Hollow Section (CHS) bracing members are also used in practice but are less common than Cee-sections.

Sensitive to second-order effects, accurately determining the shear stiffness of these upright frames is essential for seismic design and for ensuring the stability of the rack, especially for high-bay racks and racks supporting the building enclosure, where the outer rack frames must withstand cross-aisle horizontal actions due to wind loading. For static design, the shear stiffness value mainly affects the serviceability limit state rather than the ultimate limit state, yet accurately determining the transverse shear stiffness is also required to determine the cross-aisle elastic buckling load $P_{c r}$ of the upright frame as developed hereafter. For seismic design, the shear stiffness of the upright frame influences the natural frequency of the rack 
and hence the earthquake force in the cross-aisle direction. Underestimating the shear stiffness would lead to unsafe design earthquake forces.

The Rack Manufacturers Institute, RMI [3], and the former Australian Standard, AS 4084 [4], calculate the transverse shear stiffness $S_{D}$ of upright frames based on Timoshenko and Gere's [5] shear formulae, in which the upright frame shear deformation is assumed to be only due to the axial deformation of the bracing members. The shear stiffness is then used to estimate the elastic buckling load $P_{c r}$. For instance, for upright frames braced with diagonal bracing members only, the shear stiffness $S_{D}$ is given as,

$$
S_{D}=A_{d} E \sin \phi \cos ^{2} \phi
$$

and the elastic buckling load $P_{c r}$ as,

$$
P_{c r}=\frac{1}{\frac{k^{2} H^{2}}{\pi^{2} E I}+\frac{1}{S_{D}}}=\frac{\pi^{2} E I}{k^{2} H^{2}} \frac{1}{1+\frac{\pi^{2} I}{k^{2} H^{2}} \frac{1}{A_{d} \sin \phi \cos ^{2} \phi}}
$$

where $A_{d}$ is the cross-sectional area of a diagonal bracing member, $E$ is the Young's modulus, $I$ is the minimum net second moment of area of the uprights about an axis perpendicular to the plane of the upright frames, $k$ is a factor depending on the position of the loads, $H$ is the total height of the upright frame and $\phi$ is the angle between the horizontal and diagonal bracing members.

A different approach is adopted in the European Standard EN 15512 [6] and recently in the revised Australian Standard AS 4084 [7], which requires testing to calculate the transverse shear stiffness per unit length of an upright frame. The approach consists of experimentally determining the upright frame longitudinal shear stiffness and calculating the transverse shear stiffness using Timoshenko and Gere’s [5] shear formulae. In the proposed test set-up, shown in Fig. 3, an upright frame composed of at least two bracing panels is restrained in the transverse direction at two corners. One upright is pinned in the longitudinal direction at one end 
and a longitudinal load $F$ is applied at the opposite end of the other upright through its centroidal axis. This test set-up varies slightly from the set-up specified in the Federation Europeenne de la Manutention Specification, FEM [8], in which the frame was restrained in the transverse direction at each connection point between the uprights and the bracing members. This change in test set-up follows the recommendations made in [9-10].

The longitudinal displacement at the free end of the upright on which the load is applied and the load itself are recorded in the shear tests described in EN 15512 [6] and AS 4084 [7]. The stiffness $k_{t i}$, taken as the slope of the best-fit straight line of the experimental loaddisplacement curve, and Timoshenko and Gere's [5] shear theory are used to calculate the upright frame transverse shear stiffness $S_{t i}$ as,

$$
S_{t i}=\frac{k_{t i} d^{2}}{h}
$$

where $d$ is the distance between the centroidal axes of the uprights and $h$ is the length of the frame taken as the distance between the top and bottom horizontal bracing members, as shown in Fig. 3.

Very few investigations have been reported on the shear stiffness of steel storage rack upright frames consisting of cold-formed steel profiles and bolted connections. Godley and Beale [11] experimentally investigated the influence of the looseness of bracing member connections on the upright frame shear stiffness and on the ultimate load carrying capacity of pallet rack frames.

Rao et al. [12] and Sajja et al. [9-10] investigated experimentally and numerically the shear stiffness of storage rack upright frames at Oxford Brookes University. In total, 80 tests were performed according to the FEM [8] test set-up on upright frames characterised by different numbers of panels, aspect ratios of the panels, upright sizes, restraints and bracing configurations. Rao et al. [12] showed that the Timoshenko and Gere's [5] shear stiffness expression, 
given in Eq. (1) for the particular case of upright frames braced with diagonal bracing members only, may overestimate the shear stiffness by a factor up to 20. Finite Element models developed in these studies $[9-10,12]$ were not able to accurately reproduce the experimental test results and produced stiffness values 2 to 5 times greater than the test results. The FE models incorporated bolts using beam elements, a practice not currently adopted in design offices for routine checks. The authors attribute the difference between FE results and experimental test results to the joint flexibility and the distortion of the upright, caused by the eccentricity between the uprights and the bracing members at the joints, which was not considered in the FE analysis. More importantly, by considering one by one the effects of (i) the axial and flexural stiffness values of the uprights, (ii) the eccentricities between bracing members, uprights and bolts, (iii) the bending of bolts and (iv) the bolt rotational release in their FEA, Rao et al. [12] and Sajja et al. [9-10] proved that it is necessary to consider all these effects to accurately determine the upright frame shear stiffness.

However, it is not clear whether these effects would manifest themselves to a different extend if the shear deformations were induced in the transverse, rather than in the longitudinal direction, and consequently, it is not clear whether the shear stiffness obtained using the test procedure stipulated in EN 15512 [6], and now in AS 4084 [7], will produce the correct stiffness required for the stability and serviceability checks of upright frames in the cross-aisle direction, or whether a different test set-up is needed which directly measures the stiffness when the upright is subjected to shearing deformations in the transverse direction.

Therefore, an alternative test set-up was included in the revised AS 4084 [7] and is subject of investigation in this paper. 36 tests have been performed on upright frames using the original method in EN 15512 [6] (see Fig. 3) and the alternative method in AS 4084 [7] detailed in Section 2. The two methods are compared and test results are presented to demonstrate the practical use of the alternative method. Recommendations on how to use the test outcomes in 
design are also provided, and the consequences of using either the original method in EN 15512 [6] or the alternative method in AS 4084 [7] on the design of storage rack frames are discussed.

\section{ALTERNATIVE TEST SET-UP IN THE REVISED AS 4084}

The purpose of the alternative test set-up in AS 4084 [7] is to determine the overall sway stiffness of the upright frame in the cross-aisle direction by testing the frame in combined bending and shear. To achieve this purpose, a frame assembly with a minimum number of two bracing panels shall be connected to a rigid testing frame by pin-connecting the upright ends, as shown in Fig. 4. The top of the frame shall be restrained from lateral out-of-plane displacements (see Fig. 4) and a load $F$ shall be applied in the transverse direction at the elevation of the top horizontal bracing member.

The transverse displacements of the frame $\delta_{1}$ and $\delta_{2}$ at the elevations of the load application point and the bottom horizontal bracing member, respectively, shall be recorded using displacement transducers. The resulting displacement $\delta_{1}$ (Fig. 5 (a)) at the load application point is the sum of a pure bending deformation $\delta_{1,1}$ of the frame (Fig. 5 (b)) and a pure shear deformation $\delta_{1,2}$ of the frame (Fig. 5 (c)).

The combined bending and shear transverse stiffness $S_{C t i}$ of the frame in the cross-aisle direction per unit of length of the upright frame is then defined as,

$$
S_{C t i}=k_{C t i} h
$$

where $h$ is the length of the frame, shown in Fig. 4 , and $k_{C t i}$ is slope of the experimental loaddisplacement curve calculated as,

$$
k_{C t i}=\frac{F}{\delta_{1}-\delta_{2}}
$$


The transducer at the elevation of the bottom horizontal bracing member has been added after the public review of the standard and the final test method adopted by the Standard varies slightly from the one previously published in [13].

The revised AS 4084 [7] recommends calculating the design combined transverse bending and shear stiffness based on the average value from a minimum of three tests.

\section{TEST OUTCOMES}

The criteria for the analysis of racks in the cross-aisle direction are specified in Section 10.3 of EN 15512 [6] and in Section 3.3.4 of the revised AS4084 [7], in which the stability of upright frames in the cross-aisle direction "shall be demonstrated by a rational analysis" which takes into account the "shear flexibility of the bracing system". From a practical view point, this is usually achieved using FEA by reducing either the Young's modulus or the cross-sectional area of the bracing members, i.e. reducing the axial stiffness of the bracing members. Currently, the axial stiffness of the bracing members is chosen so that the FEA shear stiffness value matches the experimental shear stiffness value obtained from tests performed as per the original method in EN 15512 [6]. The calibrated FE model is hence used for serviceability checks, to calculate the elastic buckling load in the cross-aisle direction and to determine earthquake forces.

The alternative test set-up introduced in Section 2 measures the shear flexibility of the upright frame and therefore, the experimental results can also be used to check the frame stability in the cross-aisle direction. A similar FEA approach as detailed above can be used to match the FEA sway stiffness value to the experimental sway stiffness value by changing the axial stiffness of the bracing members. Section 5 illustrates the procedure for 36 tests performed using the two test methods and compares the reduced axial stiffness of the bracing members obtained from the FEA. 


\section{EXPREIMENTAL STUDY}

\subsection{General}

36 tests have been performed to determine the shear stiffness $S_{t i}$ in Eq. (3) and the combined transverse bending and shear stiffness $S_{C t i}$ in Eq. (4). The uprights frames were composed of three bracing panels and assembled from three upright types, referred to as Types A, B and C. For each type of upright, two different bracing configurations were considered. The first bracing configuration consists of circular hollow sections (CHS) assembled in an Xpattern and with pairs of horizontal bracing members as shown in Fig. 6 (a). The second bracing configuration consists of lip-to-lip Cee sections assembled in a Z-pattern as shown in Fig. 6 (b).

Fig. 7 shows the main dimensions of the uprights and Table 1 gives the main nominal properties of the profiles constituting the frames. Table 2 gives the upright frame dimensions for the three types of uprights with reference to Fig. 3 and Fig. 4.

The tests have been carried out at two different universities on similar materials but rolledformed from different steel sheet coils. Tests following the original method in EN 15512 [6] with Cee bracing members have been conducted at the University of Trento and all remaining tests have been conducted at Griffith University. In order to compare the consistency of the results between the two universities, two tests have been repeated at Griffith University on frames assembled from Type A uprights and the results are discussed in Section 4.2. Three tests have been performed per upright frame configuration. Table 3 summarises the tests performed.

For all tests, the frames were restrained from lateral out-of-plane displacements in three locations along the length of the frames at Griffith University and in four locations at the University of Trento. End plates were welded to the ends of the uprights to ensure easy connec- 
tion and restrain warping. For the tests carried out at Trento University, the bolts connecting the uprights to the bracing members were tightened using a locking torque as per the standard procedure adopted by the manufacturer during the assembly of the rack. At Griffith University, the bolts were "snug-tightened" by hand and slightly untightened to limit friction and ensure the connections were as close as possible to pinned connections. In view of the initial test results at Trento University and in accordance with the rack manufacturer, the latter arrangement was preferred for the remaining tests at Griffith University, so as to minimise as possible the high initial shear stiffness attributed to the friction between elements (see replicated test results in Section 4.2 and test results in Section 4.3). For the Z-pattern bracing configuration, the diagonal bracing members were loaded in compression which was found to give lower experimental stiffness values than loading the bracing members in tension.

Load was applied through a hydraulic jack at a quasi-static load rate. The test procedure varies slightly between the two Universities. At Trento University, the load was applied up to $6 \mathrm{kN}$, reversed to $0.5 \mathrm{kN}$ and increased up to failure. On the other hand, before commencing each test at Griffith University, the applied load was increased to about $3 \mathrm{kN}$ and to $1 \mathrm{kN}$ or 2 $\mathrm{kN}$ (depending on the frame configuration) for the original method in EN 15512 [6] and the alternative method in the revised AS 4084 [7], respectively, so as to have all elements in contact. The axial load was then reduced to $0 \mathrm{kN}$, the load-deformation curve was recorded and the load increased up to failure.

For the alternative test method in the revised AS 4084 [7], the end plate of the upright in tension tended to plastically deform and lift from its support, resulting in an increased recorded transverse displacement of the frame. Care was taken to avoid such phenomenon by efficiently clamping the end plate to the pinned support.

Fig. 8 (a) and Fig. 8 (b) show pictures of the test set-ups for the tests performed at Griffith University for the original method in EN 15512 [6] and the alternative method in the revised 
AS 4084 [7], respectively, and Fig. 9 shows the test set-up for the tests performed at the University of Trento.

\subsection{Replicated test results}

Fig. 10 shows the load-displacement curves for the three tests performed at the University of Trento and the two repeat tests performed at Griffith University on upright frames assembled from Type A uprights with Cee bracing members. All tests show similar non-linear behaviour and present a high initial stiffness. Yet, the applied load $F$ defining the transition between the high initial stiffness and the linear portion of the curve is different between the two series of tests, of about $1.5-2.0 \mathrm{kN}$ at Trento University and of about $1.0 \mathrm{kN}$ at Griffith University, as shown in Fig. 10. This difference can be attributed to the different degree of torque applied to the bolts connecting the uprights to the bracing members between the tests carried out at the two universities and to the different loading procedures adopted at the beginning of the tests, as mentioned in Section 4.1.

The unloading and reloading phase at an applied load $F$ of $6 \mathrm{kN}$ for the tests performed at Trento University can be seen in Fig. 10.

An average longitudinal frame stiffness $k_{t i}$ of $1.139 \mathrm{kN} / \mathrm{mm}$ and of $1.143 \mathrm{kN} / \mathrm{mm}$ was evaluated for tests performed at Trento University and at Griffith University, respectively. $k_{t i}$ is defined in Section 1 and calculated herein by performing a linear regression on the loaddisplacement curves between axial loads of $4 \mathrm{kN}$ and $12 \mathrm{kN}$. This range of load was selected to represent the linear portion of the load-displacement curves.

The ultimate loads differ between the two series of tests, likely due to the sections having different yield stress values as being roll-formed from different steel sheet coils. 
The similarities between the two series of tests prove that all tests were performed in a similar manner, and were repeatable, and therefore comparison between the test series is possible.

\subsection{Test results}

Fig. 11 (a) and Fig. 11 (b) show typical load-deformation curves for tests performed on upright frames assembled in an X-pattern bracing configuration (CHS bracing members) using the original method in EN 15512 [6] and the alternative method in the revised AS 4084 [7], respectively. Similarly, Fig. 12 (a) and Fig. 12 (b) show typical load-displacement curves for tests performed on upright frames assembled in a Z-pattern bracing configuration (Cee bracing members) using the two test methods.

For the X-pattern bracing configuration and CHS bracing members, the load-deformation curves show low initial stiffness (see Fig. 11), likely due to the looseness of the connections between the bracing members and the uprights. This looseness is ignored in this study as it may not be experienced if the bolts were tightened using a locking torque as per standard practice (see Section 4.1), and the slopes $k_{t i}$ and $k_{C t i}$ of the experimental test results were calculated from the linear portion of the curve as shown in Fig. 11.

For the Z-pattern bracing configuration and Cee bracing members, the load-deformation curves show high initial stiffness (see Fig. 12). Contrary to the CHS bracing members, the Cee bracing members are inserted into the flanges of the uprights with no space between them as shown in Fig. 6 (b). This tight fit is likely to generate friction between members, and therefore a sufficient moment in the connection is needed to overcome this frictional moment and induce rotation between the bracing members and the uprights, resulting in the recorded high initial stiffness. Moreover, the high initial stiffness would likely be experienced to a higher applied load $F$ if the bolts were tightened using a locking torque as per standard practice (see 
Section 4.1), as the value of the moment needed to induce rotation of the bracing members relative to the uprights would be higher than the one experienced in this study. As a result, the initial stiffness is ignored herein by calculating the slopes $k_{t i}$ and $k_{C t i}$ of the experimental test results from the linear portion of the curve as shown in Fig. 12.

The X-pattern bracing configuration usually failed by one or a combination of the following modes (i) lateral buckling of the diagonal bracing member in compression, (ii) shearing of the bracing members at the bolt hole, (iii) shearing of the bolts, and (iv) buckling of the flat part at the extremities of the CHS. The Z-pattern bracing configuration usually failed by one or a combination of the following modes (i) lateral-torsional buckling of the diagonal bracing member in compression and (ii) shearing of the bracing members at the bolt hole. Due to the Z-pattern bracing configuration having (i) only bracing members in compression, (ii) Ceesections buckling at a lower compressive load than the CHS and (iii) less material at the bolt holes for the bracing members, the Z-pattern bracing configuration failed at a lower load than the X-pattern bracing configuration.

Table 4 and Table 5 show the average experimental slopes $k_{t i}$ and upright frame shear stiffness $S_{t i}$, and average experimental slopes $k_{C t i}$ and combined bending and shear stiffness $S_{C t i}$, respectively, calculated for three tests with standard deviations for all test series listed in Table 3. The stiffness $k_{t i}$ and $k_{C t i}$ are found by performing a linear regression analysis on the linear portion of the load-deformation curves. The upright frame dimensions used to calculate the frame stiffness in Table 4 and Table 5 are given in Table 2. As seen in Table 4 and Table 5, due to (i) the non-symmetrical configuration of the Z-pattern bracing which induces significant torsion of the uprights, (ii) the weak torsional stiffness of the Cee-sections and (iii) the smaller axial stiffness of the bracing members, the frame stiffness of the Z-pattern bracing configuration is 4 to 11 times lower than the stiffness of the X-pattern bracing configuration. 


\section{FINITE ELEMENT ANALYSIS AND COMPARISON WITH EXPERI- MENTAL RESULTS}

\subsection{FE model}

The combined experimental-FEA approach introduced in Section 3 is used in this section to compare the two test methods, explain the difference in shear stiffness derived from the methods and the influence of using the alternative method in designing steel storage racks. An FE model of the upright frame is built using beam elements in Abaqus [14] and calibrated against the experimental stiffness value by reducing the axial stiffness of the bracing members. The FE model is similar to the FE model of drive-in rack structures published in [15-16] and checked against full-scale experimental tests. The beams are modelled using elastic material. The model considers geometric eccentricities and second-order geometric non-linear analysis is carried out. Member imperfections are not considered. The different members comprising the rack are modelled as follow:

- The uprights are modelled at their centroidal axis using type B32OS elements, which consider shear centre eccentricity and warping torsion.

- The bracing members are modelled at their centroidal axis accounting for the eccentricity between the centroidal axis and the location of the bolt holes connecting the bracing members to the uprights (refer to [15]). Element type B33, which considers the shear centre eccentricity but ignores warping, is used for the CHS bracing members and element type B32OS is used for the Cee bracing members. The length of the bracing members is taken as the length between bolt holes.

Following current industry practice, bolts are not modelled explicitly in the FEA but representing by using links connecting the uprights to the bracing members as follow: 
- Pinned connections about an axis perpendicular to the plane of the frame are used between the bracing members and the uprights shown as local z-axis in Fig. 13 (bolt axis).

- As the Cee bracing members occupy the entire space between the flanges of the uprights (see Fig. 6 (b)), the rotation between the bracing members and the uprights about an axis in the plane of the frame and perpendicular to the centroidal axis of the bracing member (shown as local y-axis in Fig. 13 (a)) is considered as rigid. In reality, this connection is likely to be semi-rigid and the stiffness value of this connection requires further research outside the scope of this paper.

- The CHS bracing members are free to rotate about an axis in the plane of the frame and perpendicular to the centroidal axis of the bracing member (see Fig. 6 (a)) and the rotation is therefore released about that axis (shown as local y-axis in Fig. 13 (b)) in the model.

The boundary conditions are chosen to match the experimental boundary conditions described in Section 4.1 with reference to Sections 1 and 2. Because the end plates were welded to the uprights in the tests, warping is restrained at the ends of the uprights in the FEA. The Young's modulus $E$ is taken as $210 \mathrm{GPa}$. The main nominal properties of the cross-sections used in the FEA are given in Table 1.

\subsection{FE results and comparison with experimental results}

Table 6 gives the ratios of the FE stiffness $k_{t i, F E(\text { nom })}$ (or $k_{C t i, F E(\text { nom })}$ ) evaluated using the nominal cross-sectional area $A_{\text {nom }}$ of the bracing members given in Table 1 to the experimental stiffness $k_{t i}$ (or $k_{C t i}$ ). Table 6 shows that when using the nominal cross-sectional area of the bracing members in the FEA, the analysis overestimates the experimental stiffness by a factor of 9 to 25 for the original method in EN 15512 [6], a result higher than the findings in 
[12] (see Section 1), and by a factor of 3 to 16 for the alternative method in the revised AS 4084 [7]. Even if the experimental stiffness values are of the same order of magnitude for all Z-pattern bracing configurations (see Table 4 and Table 5), the FEA does not give similar stiffness values for the upright frames assembled from C35×20×1.2 (Type A upright) and C35×35×1.5 (Type B and C uprights) as shown in Table 6 . This difference is likely due to the idealised pinned/rigid connections between the bracing members and the uprights in the FEA, especially regarding the torsion of the upright. Also, the actual semi-rigid behaviour of the connection is likely to be different for the narrow $(\mathrm{C} 35 \times 20 \times 1.2)$ and wide $(\mathrm{C} 35 \times 35 \times 1.5)$ Cee bracing members and would, in part, explain the difference in shear stiffness. Experimental visual observations showed that the rotations at the ends of the bracing members do not fully follow the torsion of the upright, and this connection is believed to be the key to understanding the actual behaviour of cold-formed bolted upright frames. Besides, FEA shows that the value of the rotational stiffness of the connection between the bracing members and the uprights about an axis in the plane of the frame and perpendicular to the centroidal axis of the bracing member significantly influences the frame shear stiffness.

As introduced in Section 3, the cross-sectional area of the bracing members is now reduced in the FEA to match the average experimental stiffness $k_{t i}$ and $k_{C t i}$ given in Table 4 and Table 5, respectively. The ratios of the nominal cross-section area $A_{\text {nom }}$ to the reduced crosssectional area $A_{\text {reduced }}$ of the bracing members for the FE stiffness $k_{t i, F E}$ (or $k_{C t i, F E}$ ) evaluated to match the experimental stiffness $k_{t i}$ (or $k_{C t i}$ ) to an accuracy of $0.1 \%$ are given in Table 6 . The results show that using the alternative method in the revised AS 4084 [7] results in a larger reduced axial stiffness of the bracing members compared to the axial stiffness obtained using the original method in EN 15512 [6]. This demonstrates that the two methods are not equivalent, that they measure different "quantities" and therefore the shear deformation is different if the load is induced in the transverse, rather than the longitudinal direction. Because the al- 
ternative method in the revised AS 4084 [7] measures the deformation of the frame in the direction that it would occur in during service, the alternative method is believed to be more appropriate than the original method in EN 15512 [6].

To further compare the results of the two methods, the actual transverse shear stiffness $S_{t i}$ is estimated herein by running the FE model of the frames with high value of the Young's modulus of the uprights, so as to increase the bending stiffness $E I$ and suppress the pure bending deformation $\delta_{1,1}$ of the frame, as shown in Fig. 5 (b). The numerical "pure" transverse shear stiffness values are compared to the ones shown in Table 4 as obtained from the experimental test results following the original method in EN 15512 [6]. The results are presented in Table 7 and show that the shear stiffness arising from loading the frames in longitudinal shear produces stiffness $S_{t i}$ values that are 1.6 to 2.0 times lower than when loading the frames in transverse shear for the CHS bracing members, and 1.2 to 1.5 times lower for the Cee bracing members.

Therefore, it is considered likely that performing tests following the original method would lead to conservative and uneconomical designs. For the upright frames tested, the use of the reduced cross-sectional area evaluated following the EN 15512 [6] approach (fourth column of Table 6) in an FE analysis of the frames would result in combined bending and shear stiffness values $S_{C t i}$ that are 1.4 to 1.7 times lower than the ones found from the alternative method in AS 4084 [7] for the CHS bracing members (See Table 7), and 1.1 to 1.4 lower for the Cee bracing members (See Table 7).

These results have significant impact on the rack design, especially for high bay storage racks and racks supporting the building enclosure where serviceability governs: in other words, using the results for the alternative method in AS 4084 [7] would reduce the crossaisle displacement of the frame by a factor of 1.1 to 1.7 when compared to using the results from the original method in EN 15512 [6], for the upright frames investigated in this paper. 


\section{CONCLUSIONS}

This paper describes the current methods for determining the shear stiffness of coldformed steel storage rack upright frames. The new test method introduced in AS 4084 [4] is the subject of investigation in this paper. The method deforms the frame in its transverse direction and is consequently considered more appropriate than the EN 15512 [6] test set-up.

36 tests on upright frames assembled from three different types of uprights and two different bracing pattern configurations have been carried out following the original and alternative test methods in EN 15512 [6] and the revised AS 4084 [7], respectively. The results are presented, compared and discussed in this paper. Recommendations on how to use the test outcomes in design are also presented. Based on these recommendations, this paper shows that the two test methods do not give similar values of reduced axial stiffness of the bracing members to be used in design, and therefore are not equivalent. For the upright frames considered in this study, the alternative method in the revised AS 4084 [7] yields a transverse shear stiffness values $S_{t i}$ of 1.2 to 2.0 times the one resulting from the original method in EN 15512 [6].

Further research is needed to better understand the response and the influence of the semirigid connections between the bracing members and the uprights. This connection is thought to be the main key to understand the shear behaviour of cold-formed steel bolted frames.

\section{References}

[1] J.M. Davies, Stability of unbraced pallet racks, in: 5th International Speciality Conference on Cold-Formed Steel Structures, St. Louis, Missouri, U.S.A., 1980, pp. 409-428.

[2] J.M. Davies, Down-aisle stability of rack structures, in: 11th International Specialty Conference on Cold-Formed Steel Structure St Louis, Missouri, U.S.A., 1992, pp. 417-435. 
[3] RMI, Specification for the design, testing and utilization of industrial steel storage racks, Rack Manufacturers Institute, Charlotte, U.S.A., 2008.

[4] AS 4084, Steel storage racking, Standards Australia, Sydney, Australia, 1993.

[5] S.P. Timoshenko, J.M. Gere, Theory of elastic stability, 2nd edition, McGraw-Hill Book Company, Inc, New York, U.S.A., 1961.

[6] EN 15512, Steel static storage systems - Adjustable pallet racking systems - Principles for structural design, European Committee for Standardization (CEN), Brussels, Belgium, 2009. [7] AS 4084, Steel storage racking, Standards Australia, Sydney, Australia, 2012.

[8] FEM, Section X - Recommendations for the design of steel static pallet racking and shelving, Federation Europeenne de la Manutention, Brussels, Belgium, 1998.

[9] S.R. Sajja, R.G. Beale, M.H.R. Godley, Factors affecting the shear stiffness of pallet rack uprights, in: D. Camotim, et al. (Eds.) Stability and Ductility of Steel Structures, Lisbon, Portugal, 2006, pp. 365-372.

[10] S.R. Sajja, R.G. Beale, M.H.R. Godley, Shear stiffness of pallet rack upright frames, Journal of Constructional Steel Research, 64 (2008) 867-874.

[11] M.H.R. Godley, R.G. Beale, Investigation of the effects of looseness of bracing components in the cross-aisle direction on the ultimate load-carrying capacity of pallet rack frames, Thin-Walled Structures, 46 (2008) 848-854.

[12] S.S. Rao, R.G. Beale, M.H.R. Godley, Shear stiffness of pallet rack upright frames, in: 7th International Speciality Conference on Cold-Formed Steel Structures, Orlando, Florida, U.S.A., 2004, pp. 295-311.

[13] B.P. Gilbert, K.J.R. Rasmussen, Determining the transverse shear stiffness of steel storage rack upright frames, in: D. Dubina, V. Ungureanu (Eds.) 6th International Conference on Thin-Walled Structures, Timisoara, Romania, 2011, pp. 821-828.

[14] Abaqus, Abaqus ver. 6.10 - User manual, ABAQUS, Inc., Providence, U.S.A., 2010. 
[15] B.P. Gilbert, K.J.R. Rasmussen, Finite Element modelling of steel drive-in rack structures, Research Report R901, School of Civil Engineering, The University of Sydney, Australia, 2009.

[16] B.P. Gilbert, K.J.R. Rasmussen, Drive-in steel storage racks I: Stiffness test and 3D load transfer mechanisms, ASCE Journal of Structural Engineering (In press), (2012). 
Table 1: Main nominal section properties

\begin{tabular}{lccccc}
\hline Member & $\begin{array}{c}\text { Gross area } \\
\left(\mathrm{mm}^{2}\right)\end{array}$ & $\begin{array}{c}\mathrm{I}_{\text {major axis }} \\
\left(\mathrm{mm}^{4}\right)\end{array}$ & $\begin{array}{c}\mathrm{I}_{\text {minor axis }} \\
\left(\mathrm{mm}^{4}\right)\end{array}$ & $\begin{array}{c}\mathrm{J} \\
\left(\mathrm{mm}^{4}\right)\end{array}$ & $\begin{array}{c}\mathrm{I}_{\text {warping }} \\
\left(\mathrm{mm}^{6}\right)\end{array}$ \\
\hline Type A upright & 484.0 & $4.34 \times 10^{5}$ & $1.91 \times 10^{5}$ & 491.9 & $2.21 \times 10^{8}$ \\
Type B upright & 674.0 & $1.34 \times 10^{6}$ & $2.60 \times 10^{5}$ & 802.2 & $6.00 \times 10^{8}$ \\
Type C upright & 784.6 & $2.01 \times 10^{6}$ & $7.73 \times 10^{5}$ & 991.6 & $5.80 \times 10^{9}$ \\
CHS 30×1.5 & 134.3 & $1.37 \times 10^{4}$ & $1.37 \times 10^{4}$ & $2.74 \times 10^{4}$ & -- \\
C35 $\times 20 \times 1.2$ & 100.0 & $1.83 \times 10^{4}$ & $4.60 \times 10^{3}$ & 47.5 & $1.79 \times 10^{6}$ \\
C35 $\times 35 \times 1.5$ & 168.6 & $3.49 \times 10^{4}$ & $2.43 \times 10^{4}$ & 125.4 & $8.45 \times 10^{6}$ \\
\hline
\end{tabular}

Table 2: Upright frame dimensions

\begin{tabular}{cccc}
\hline$h(\mathrm{~mm})$ & & $d(\mathrm{~mm})$ \\
& Type A upright & Type B upright & Type C upright \\
\hline 3432 & 948.9 & 953.1 & 933.5 \\
\hline
\end{tabular}

Table 3: Tests performed

\begin{tabular}{|c|c|c|c|c|}
\hline Testing method & $\begin{array}{c}\text { Bracing pat- } \\
\text { tern }\end{array}$ & Bracing type & Upright type & University \\
\hline \multirow[t]{6}{*}{ Original method } & \multirow[t]{3}{*}{$X$} & CHS $30 \times 1.5$ & A & Griffith \\
\hline & & CHS $30 \times 1.5$ & B & Griffith \\
\hline & & CHS $30 \times 1.5$ & $\mathrm{C}$ & Griffith \\
\hline & \multirow[t]{3}{*}{$\mathrm{Z}$} & C $35 \times 20 \times 1.2$ & A & Trento/Griffith \\
\hline & & C $35 \times 35 \times 1.5$ & B & Trento \\
\hline & & C $35 \times 35 \times 1.5$ & $\mathrm{C}$ & Trento \\
\hline \multirow[t]{6}{*}{ Alternative method } & \multirow[t]{3}{*}{$\mathrm{X}$} & CHS $30 \times 1.5$ & A & Griffith \\
\hline & & CHS $30 \times 1.5$ & B & Griffith \\
\hline & & CHS $30 \times 1.5$ & $\mathrm{C}$ & Griffith \\
\hline & \multirow[t]{3}{*}{$\mathrm{Z}$} & C $35 \times 20 \times 1.2$ & A & Griffith \\
\hline & & C $35 \times 35 \times 1.5$ & B & Griffith \\
\hline & & C $35 \times 35 \times 1.5$ & $\mathrm{C}$ & Griffith \\
\hline
\end{tabular}

Table 4: EN 15512 [6] experimental average slope $k_{t i}$ and frame shear stiffness $S_{t i}$ (original test method)

\begin{tabular}{cccccccc}
\hline $\begin{array}{c}\text { Bracing type } \\
\text { / pattern }\end{array}$ & $\begin{array}{c}\text { Upright } \\
\text { type }\end{array}$ & $\begin{array}{c}\text { Average } \\
(\mathrm{kN} / \mathrm{mm})\end{array}$ & $\begin{array}{c}\text { St. dev. } \\
(\mathrm{kN} / \mathrm{mm})\end{array}$ & $\mathrm{CoV}$ & $\begin{array}{c}k_{t i} \\
(\mathrm{kN})\end{array}$ & $\begin{array}{c}S_{t i} \\
(\mathrm{kN})\end{array}$ & $\mathrm{CoV}$ \\
\hline CHS / X & A & 4.62 & 0.224 & 0.048 & 1213.0 & 58.7 & 0.048 \\
& $\mathrm{~B}$ & 4.59 & 0.045 & 0.010 & 1215.8 & 11.9 & 0.010 \\
& $\mathrm{C}$ & 5.61 & 0.131 & 0.023 & 1425.3 & 33.1 & 0.023 \\
Cee / Z & A & 1.14 & 0.058 & 0.051 & 298.9 & 15.1 & 0.051 \\
& B & 0.56 & 0.009 & 0.016 & 148.1 & 2.4 & 0.016 \\
& C & 0.78 & 0.019 & 0.024 & 197.7 & 4.9 & 0.024 \\
\hline
\end{tabular}


Table 5: AS 4084 [7] experimental average slope $k_{C t i}$ and frame combined bending and shear stiffness $S_{C t i}$ (alternative test method)

\begin{tabular}{cccccccc}
\hline $\begin{array}{c}\text { Bracing type } \\
\text { / pattern }\end{array}$ & $\begin{array}{c}\text { Upright } \\
\text { type }\end{array}$ & $\begin{array}{c}k_{C t i} \\
\text { Average } \\
(\mathrm{kN} / \mathrm{mm})\end{array}$ & $\begin{array}{c}\text { St. dev. } \\
(\mathrm{kN} / \mathrm{mm})\end{array}$ & $\mathrm{CoV}$ & $\begin{array}{c}S_{C t i} \\
\text { Average } \\
(\mathrm{kN})\end{array}$ & $\begin{array}{c}\text { St. dev. } \\
(\mathrm{kN})\end{array}$ & $\mathrm{CoV}$ \\
\hline CHS / X & A & 0.57 & 0.035 & 0.061 & 1943.7 & 118.7 & 0.061 \\
& B & 0.57 & 0.005 & 0.009 & 1960.8 & 17.6 & 0.009 \\
& C & 0.56 & 0.045 & 0.081 & 1915.1 & 154.6 & 0.081 \\
Cee / Z & A & 0.089 & 0.003 & 0.033 & 306.7 & 10.2 & 0.033 \\
& B & 0.051 & 0.004 & 0.080 & 174.6 & 14.1 & 0.080 \\
& C & 0.076 & 0.005 & 0.065 & 260.4 & 16.8 & 0.065 \\
\hline
\end{tabular}

Table 6: Experimental to FEA results comparison

\begin{tabular}{cccccc}
\hline \multirow{2}{*}{$\begin{array}{c}\text { Bracing type } \\
\text { / pattern }\end{array}$} & $\begin{array}{c}\text { Upright } \\
\text { type }\end{array}$ & $\begin{array}{c}\text { EN 15512 [6] (original meth- } \\
\text { od) }\end{array}$ & \multicolumn{2}{c}{$\begin{array}{c}\text { AS 4084 [7] (alternative } \\
\text { method) }\end{array}$} \\
\hline CHS / X & A & 9.2 & 12.9 & 3.3 & 6.9 \\
& B & 9.8 & 12.5 & 3.9 & 7.0 \\
& C & 8.9 & 11.5 & 8.7 & 8.0 \\
Cee / Z & A & 7.8 & 17.9 & 6.2 & 16.0 \\
& B & 25.5 & 65.6 & 16.9 & 52.7 \\
& C & 23.4 & 54.1 & 14.0 & 38.6 \\
\hline
\end{tabular}

Table 7: Comparison of “pure' transverse shear stiffness $S_{t i}$ and combined transverse bending and shear stiffness $S_{C t i}$ estimated for the original and alternative test methods

\begin{tabular}{cccc}
\hline $\begin{array}{c}\text { Bracing type } \\
\text { / pattern }\end{array}$ & $\begin{array}{c}\text { Upright } \\
\text { type }\end{array}$ & $S_{t i \text { (Alternative) }} / S_{t i \text { (Original) }}$ & $S_{C t i \text { (Alternative) }} / S_{C t i \text { (Original) }}$ \\
\hline CHS / X & A & 2.04 & 1.69 \\
& B & 1.94 & 1.65 \\
& C & 1.59 & 1.37 \\
Cee / Z & A & 1.24 & 1.10 \\
& B & 1.35 & 1.23 \\
& C & 1.49 & 1.37 \\
\hline
\end{tabular}




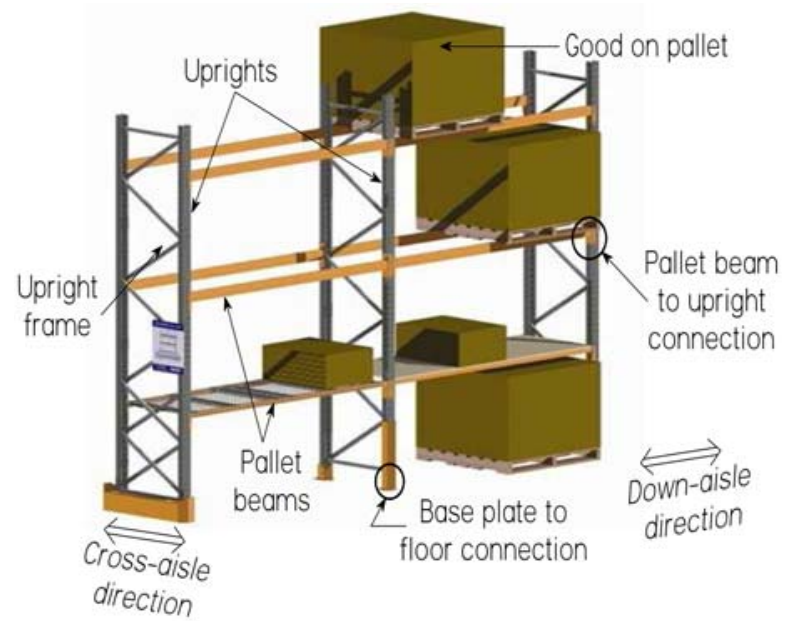

Fig. 1: Typical storage rack

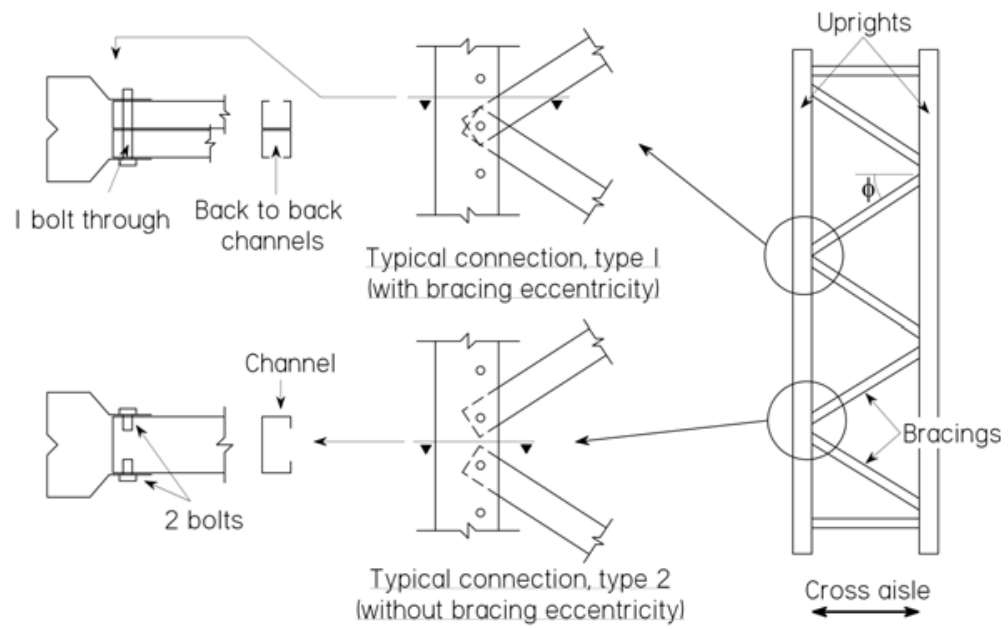

Fig. 2: Typical upright frame
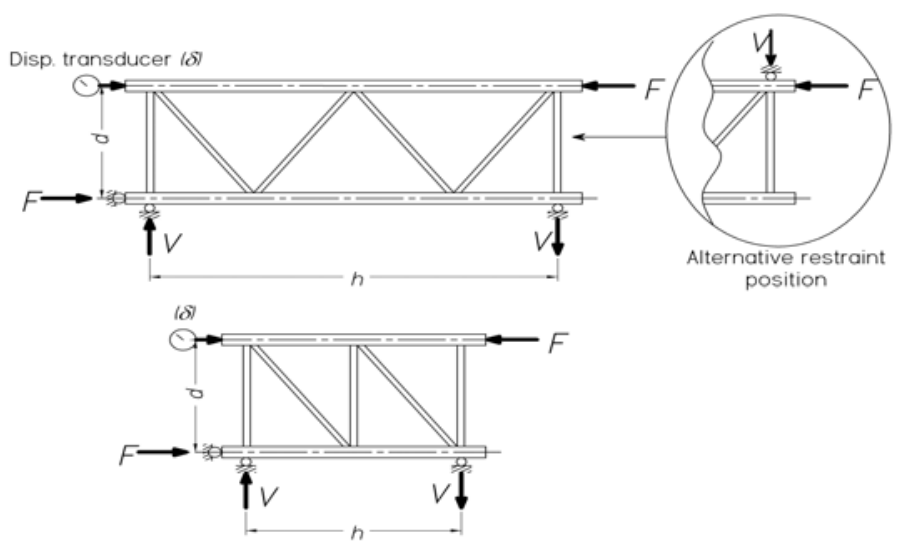

Fig. 3: Upright frame shear stiffness test set up in EN 15512 [6] 


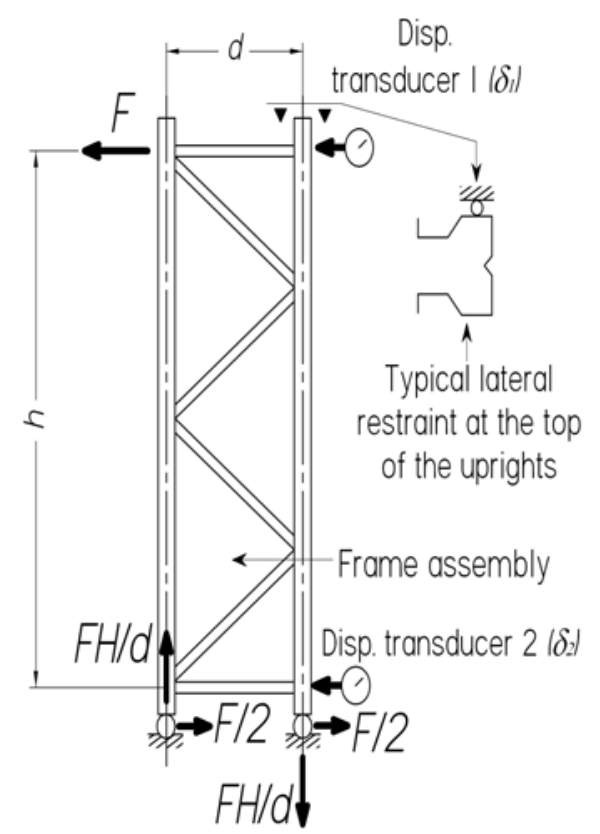

Fig. 4: Alternative test set-up in revised AS 4084 [7]

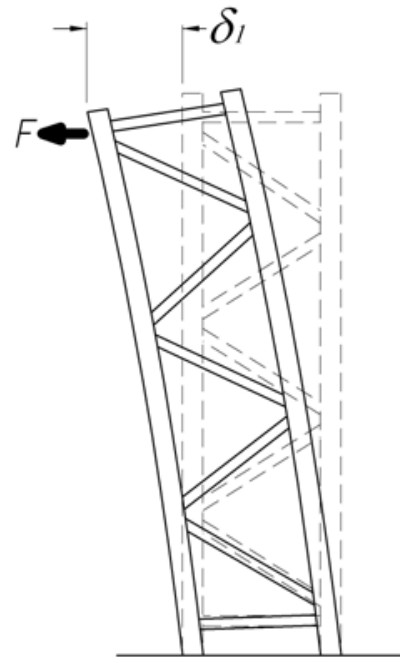

(a)

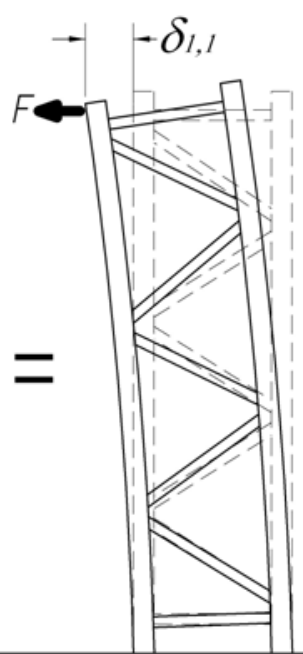

(b)

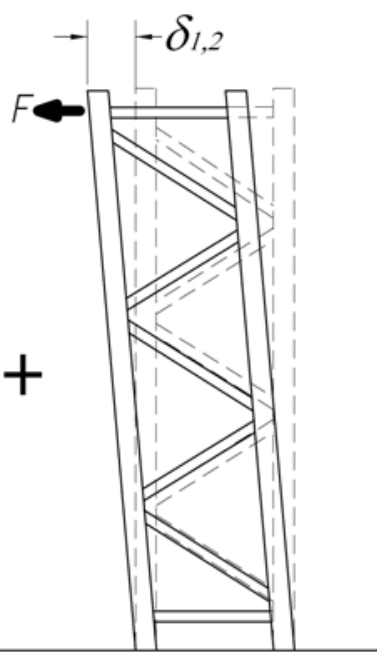

(c)

Fig. 5: Upright frame deformation (a) total deformation, (b) pure bending deformation and (c) pure shear deformation 


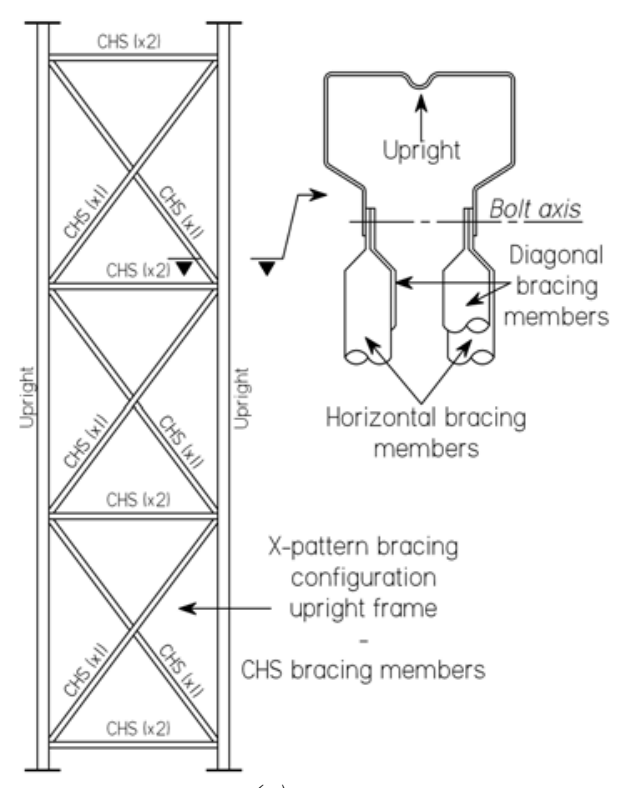

(a)

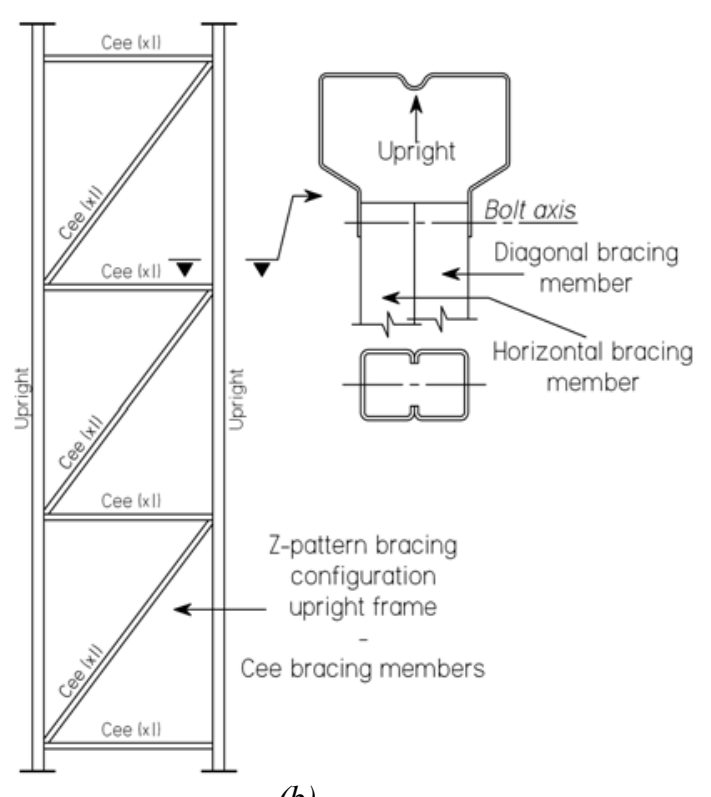

(b)

Fig. 6: Tested configurations, (a) X-pattern bracing configuration with CHS bracing members and (b) Z-pattern bracing configuration with Cee bracing members

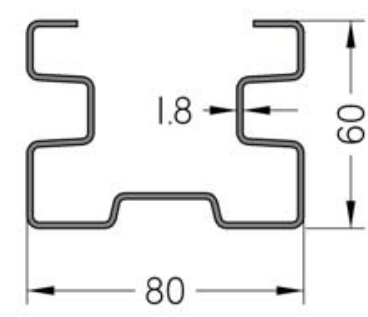

(a)

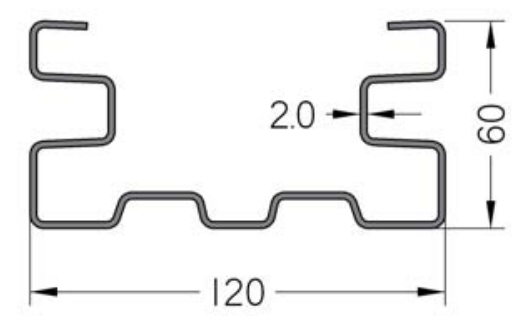

(b)

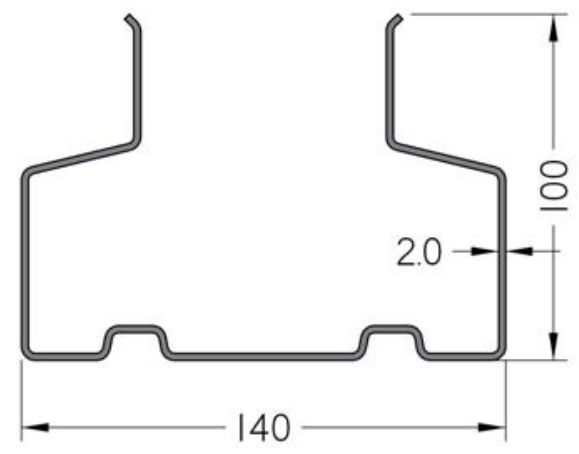

(c)

Fig. 7: Upright (a) Type A, (b) Type B and (c) type C

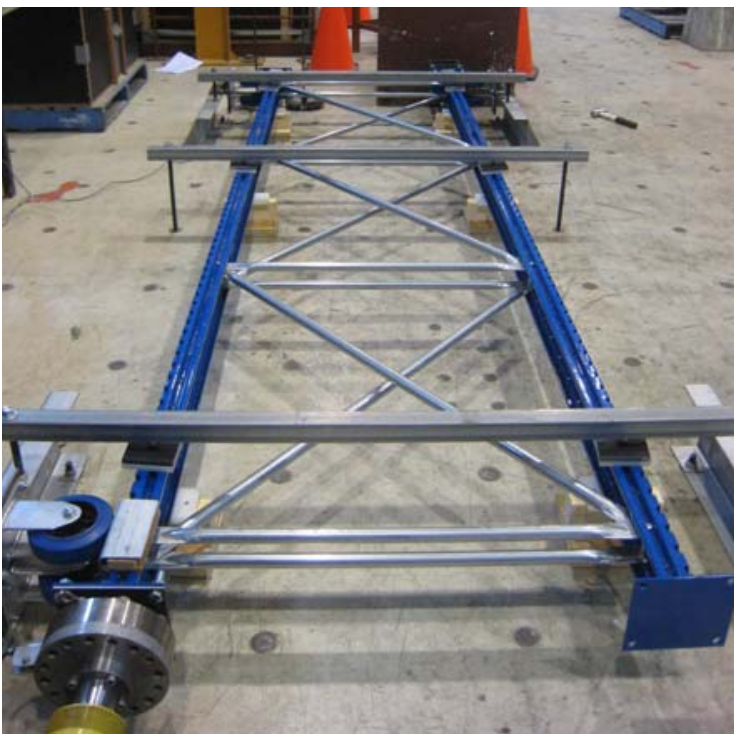

(a)

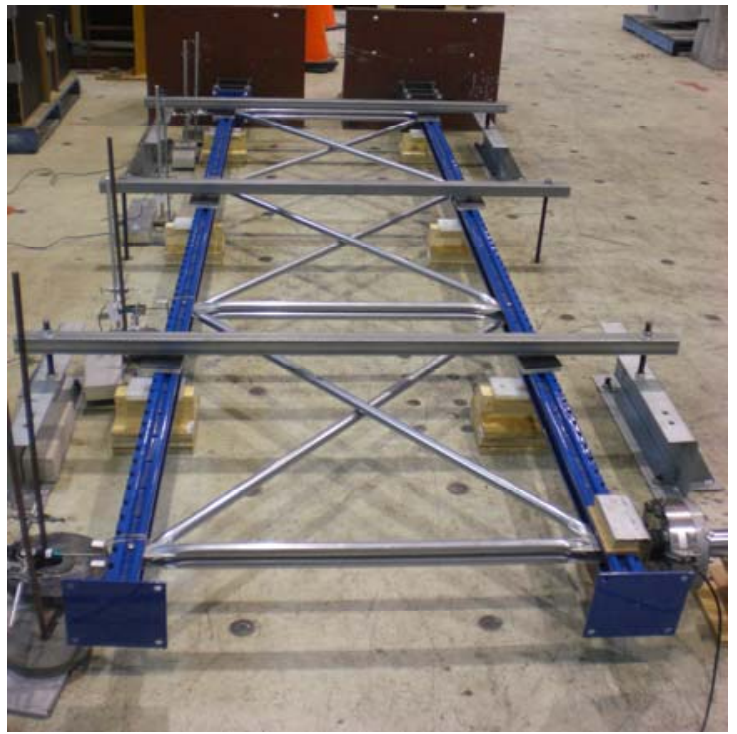

(b)

Fig. 8: Pictures of the test set-ups for the tests performed at Griffith University for (a) the original method in EN 15512 [6] and (b) the alternative method in revised AS 4084 [7] 


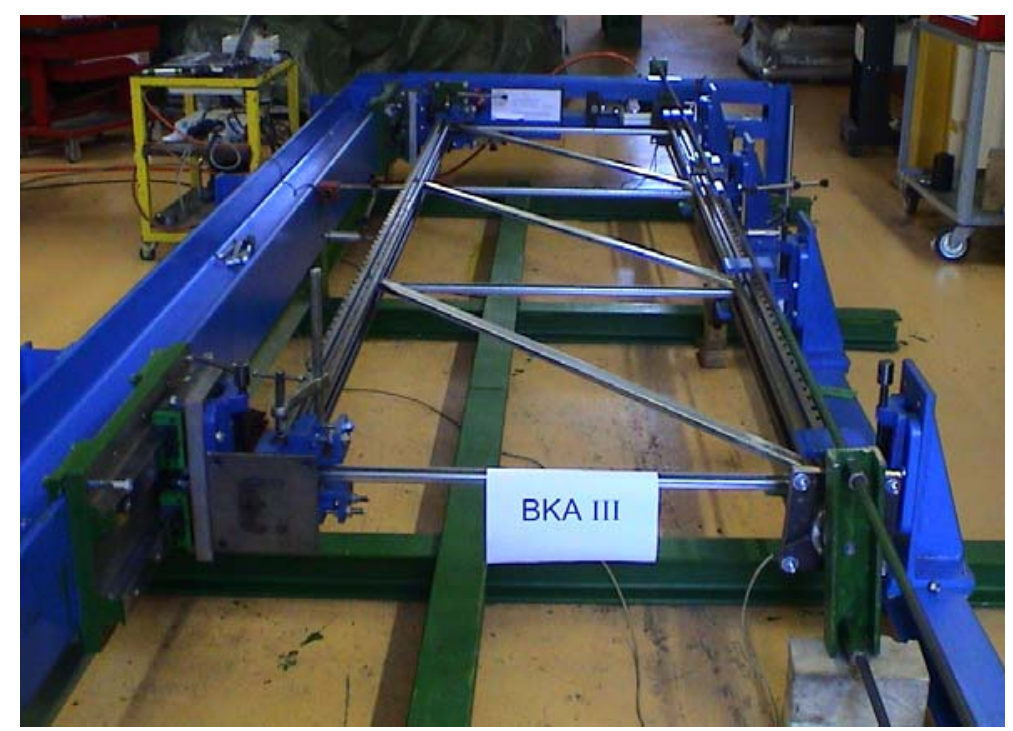

Fig. 9: Pictures of the test set-up for the tests performed at the University of Trento for the original method in EN 15512 [6]

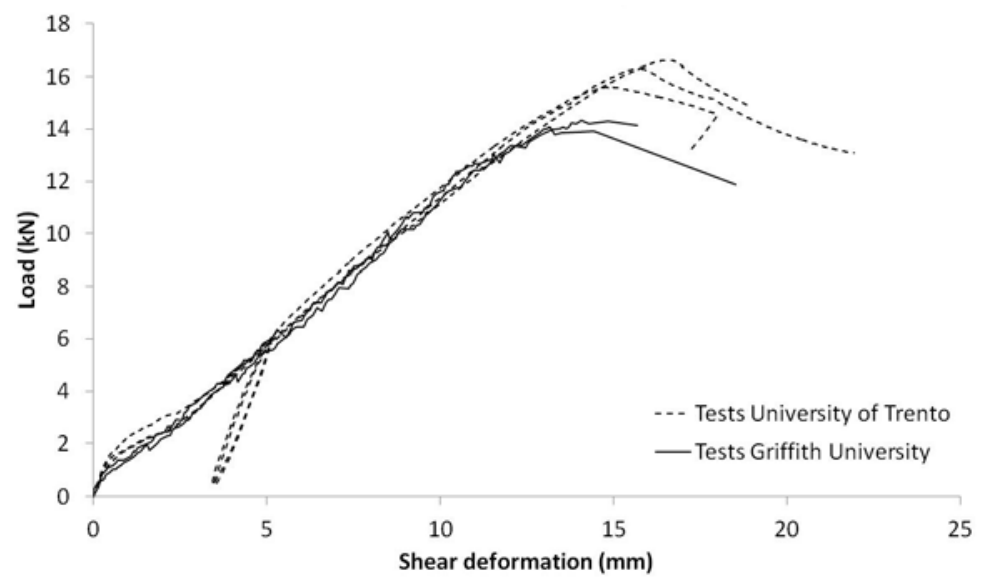

Fig. 10: Repeat tests performed at the University of Trento and Griffith University

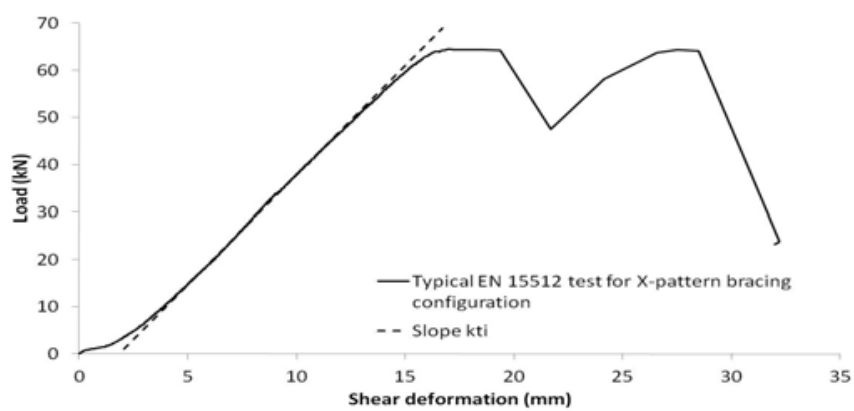

(a)

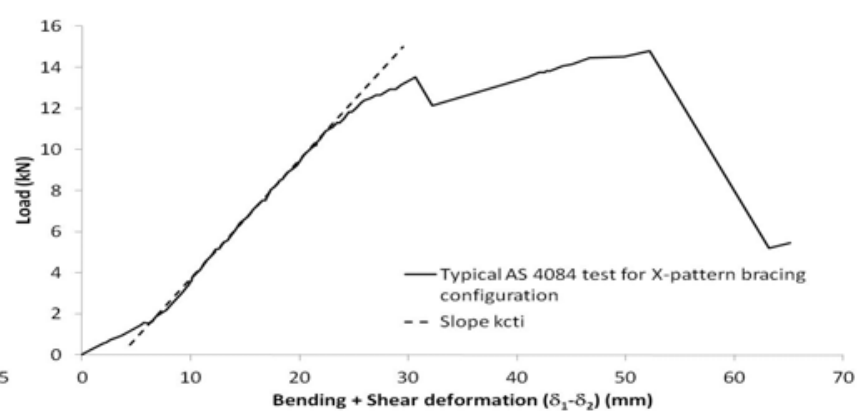

(b)

Fig. 11: Typical test results shown herein for a frame assembled from Type B upright in an X-pattern bracing configuration (CHS bracing members) for (a) the original method in EN 15512 [6] and (b) the alternative method in revised AS 4084 [7] 


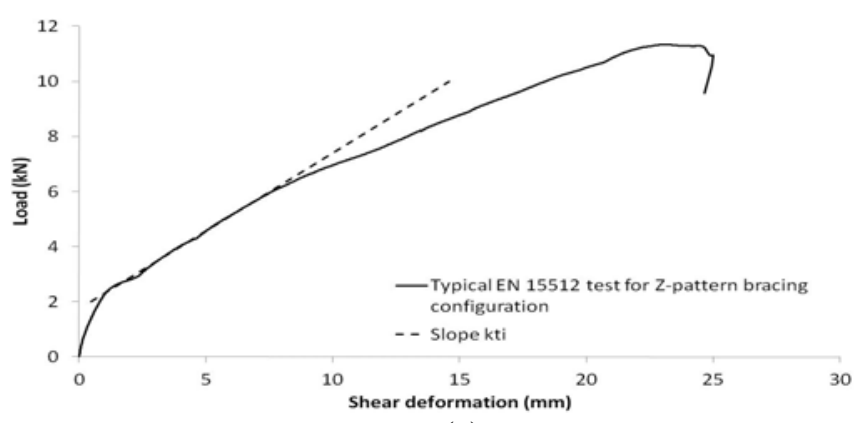

(a)

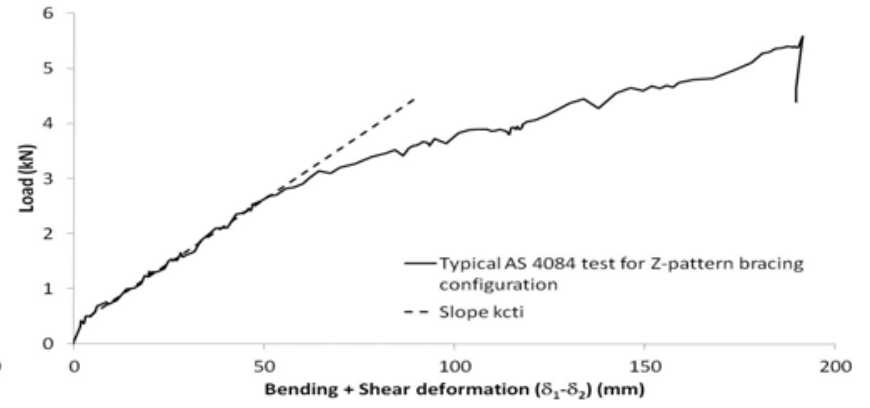

(b)

Fig. 12: Typical test results shown herein for a frame assembled from Type B upright in an Z-pattern bracing configuration (Cee bracing members) for (a) the original method in EN 15512 [6] and (b) the alternative method in revised AS 4084 [7]

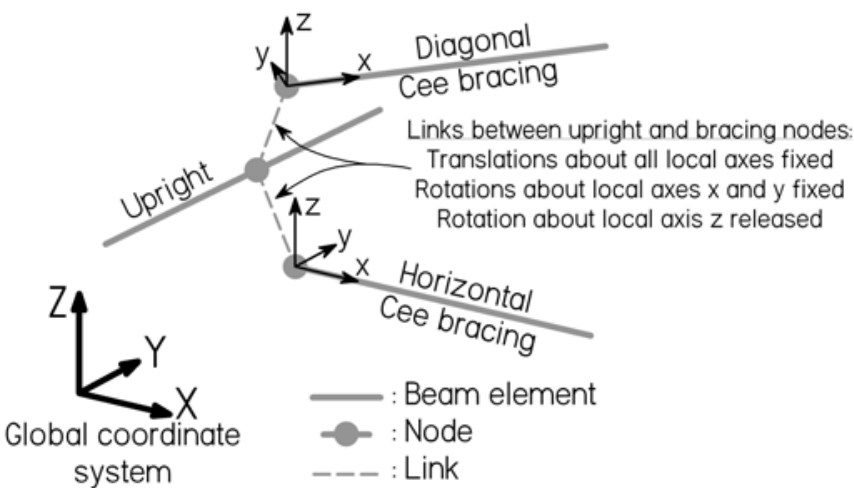

(a)

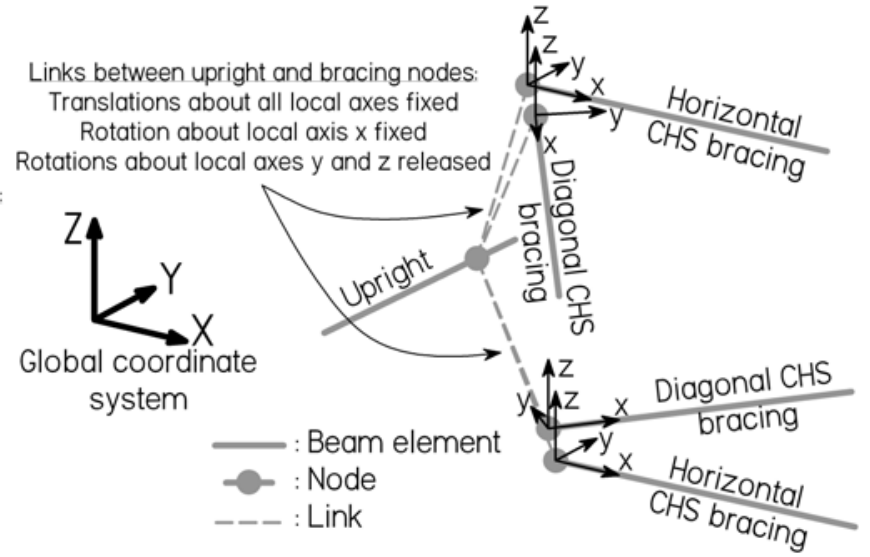

(b)

Fig. 13: Connection between uprights and bracing members in the FE model for (a) Z-pattern bracing configuration (Cee bracing members) and (b) X-pattern bracing configuration (CHS bracing members) 